\title{
Secondary extinction in Pavlovian fear conditioning
}

\author{
Drina Vurbic • Mark E. Bouton
}

Published online: 1 February 2011

(C) Psychonomic Society, Inc. 2011

\begin{abstract}
Pavlov (1927/1960) reported that following the conditioning of several stimuli, extinction of one conditioned stimulus (CS) attenuated responding to others that had not undergone direct extinction. However, this secondary extinction effect has not been widely replicated in the contemporary literature. In three conditioned suppression experiments with rats, we further explored the phenomenon. In Experiment 1, we asked whether secondary extinction is more likely to occur with target CSs that have themselves undergone some prior extinction. A robust secondary extinction effect was obtained with a nonextinguished target CS. Experiment 2 showed that extinction of one CS was sufficient to reduce renewal of a second CS when it was tested in a neutral (nonextinction) context. In Experiment 3, secondary extinction was observed in groups that initially received intermixed conditioning trials with the target and nontarget CSs, but not in groups that received conditioning of the two CSs in separate sessions. The results are consistent with the hypothesis that CSs must be associated with a common temporal context during conditioning for secondary extinction to occur.
\end{abstract}

Keywords Classical conditioning · Fear conditioning . Extinction $\cdot$ Secondary extinction $\cdot$ Generalization

In Pavlovian conditioning, a neutral cue acquires the ability to elicit a response as a result of pairings with a biologically relevant unconditional stimulus (US). The response to this cue, or conditional stimulus (CS), can later be extinguished by repeatedly presenting the CS alone. Pavlov (1927/1960,

D. Vurbic $\cdot$ M. E. Bouton $(\square)$

Department of Psychology, University of Vermont,

2 Colchester Ave.,

Burlington, VT 05401-0134, USA

e-mail: mark.bouton@uvm.edu pp. 54-57) reported that following conditioning of multiple CSs, extinction of one CS also attenuated responding to others that had not undergone any extinction. For example, his associate Babkin demonstrated the effect in at least one dog by first pairing three distinct stimuli (a buzzer, a metronome pulse, and tactile stimulation) with a US that elicited salivation. Immediately following conditioning, the metronome was presented for several trials without the US until the salivary response was extinguished. When the other two CSs were then tested (one CS of the same modality and one CS that was highly dissimilar), the responses to them were greatly attenuated even though neither CS had undergone any extinction. The finding that extinction of one CS can decrease responding to a second $\mathrm{CS}$ is known as secondary extinction (Pavlov, 1927/1960).

Although Pavlov's (1927/1960) findings are theoretically significant, over the years there has been only scattered interest in the secondary extinction phenomenon. Moreover, the contemporary literature contains several failures to observe the effect. The relevant contemporary research has been conducted mainly in fear conditioning. In three conditioned suppression experiments reported by Richards and Sargent (1983), a modest secondary extinction effect was found in the first experiment but was not replicated in the subsequent two. Two other reports using the conditioned suppression preparation failed to demonstrate the secondary extinction effect. In two experiments, Bouton and King (1983) paired a tone and a light with a shock US in separate sessions and reported that extinction of the tone CS had no effect on suppression to the light CS when it was tested later. In three experiments, Kasprow, Schachtman, Cacheiro, and Miller (1984) likewise reported null results, using both lick suppression and leverpress suppression paradigms. 
More recently, Ledgerwood, Richardson, and Cranney (2005) reported a secondary extinction effect in rats administered D-cycloserine (DCS) immediately following a session of fear extinction. DCS, a partial agonist of the NMDA receptor, has been shown to facilitate extinction of conditioned fear in rats and in humans (see, e.g., Vervliet, 2008, for a review). Using the conditioned freezing method, Ledgerwood et al. found that rats treated with DCS following extinction of a light CS froze significantly less to a tone than did a group given saline after extinction. However, unlike the results reported by Pavlov (1927/ 1960), there was no effect of extinction in groups not given DCS: Comparison of the saline-treated extinction group with nonextinguished controls showed no differences in freezing on the test. This additional failure to find a secondary extinction effect, like the previous ones, suggests that we do not yet understand the conditions that favor secondary extinction.

In contrast, Rescorla and Cunningham (1977, 1978) reported two erasure effects in conditioned suppression that may be considered examples of secondary extinction. In their experiments, extinction trials with a light CS prevented both reinstatement (1977) and spontaneous recovery (1978) of fear to an extinguished tone target CS. The authors suggested that extinction trials with the light weakened the memorial representation of the US. As a result, the weak US representation supported less conditioned responding when it was later retrieved by the tone. Although this account explains the effects they reported, similar secondary extinction results have generally not been obtained in other experiments, as described above. In fact, the failures to find secondary extinction typically employed a larger number of extinction trials; more extensive extinction might be expected to more thoroughly depress the US representation. However, unlike the other experiments on secondary extinction, the target CSs in Rescorla and Cunningham's erasure studies were extinguished prior to the tests for reinstatement and spontaneous recovery. There are grounds for thinking that extinction training would have rendered the targets more sensitive to secondary extinction (see the introduction to Experiment 1). Thus, contemporary failures to replicate secondary extinction might not have tested the effect under optimal conditions. Pavlov's (1927/1960) description of the original secondary extinction procedure did not mention any extinction of the target CSs, but the experimental history of his subjects is unknown.

Given this background, the present experiments were designed to further explore secondary extinction in the conditioned suppression preparation. We began by asking whether secondary extinction is indeed more readily observed with a target CS that has undergone some extinction prior to testing. Surprisingly, Experiment 1 produced evidence of secondary extinction with a target CS that had not received any previous extinction. Experiment 2 then confirmed secondary extinction in the form of an erasure effect in which extinction trials with one CS weakened the renewal of fear of a second extinguished CS when it was tested in a neutral context (e.g., Bouton \& Bolles, 1979). Experiment 3 explored other conditions that might enable secondary extinction. It tested and confirmed that intermixed trials with the target and nontarget CSs during the initial conditioning phase may be necessary to obtain the secondary extinction effect. The results suggest that secondary extinction can be reliably produced in the conditioned suppression preparation and that, although it is not restricted to extinguished target CSs, it depends on the use of a conditioning procedure that encourages generalization between the CSs by associating them with a common temporal context.

\section{Experiment 1}

The first experiment examined whether a target CS that had undergone some previous extinction was especially sensitive to secondary extinction (e.g., Rescorla \& Cunningham, 1977, 1978). A variety of research has suggested that primary extinction is controlled at least partly by negative occasion setting acquired by the context in which extinction occurs, which suppresses responding to the CS (see, e.g., Bouton, 2004, for one review). Such a process might produce secondary extinction if contextual occasion setting conditioned by the first CS transfers and affects responding to the second CS. Importantly, a CS that has undergone partial extinction might be an especially sensitive transfer target. For example, Swartzentruber and Rescorla (1994) found that successful transfer of inhibition to a new CS occurred when that CS had undergone both conditioning and extinction, but not when it had been merely conditioned (see also Lamarre \& Holland, 1987). If secondary extinction is a similar result of the transfer of negative occasion setting by the extinction context, it might be easier to detect with a target CS that first undergoes conditioning and extinction.

The design of Experiment 1 is summarized in Table 1. Rats first received intermixed conditioning trials with two counterbalanced CSs, one of which (X) served as the target that was tested for secondary extinction, and the other of which $(\mathrm{Y})$ served as the CS that was extinguished prior to this test. Half of the rats were also given some initial extinction trials with $\mathrm{X}$ and, thus, were tested with a partially extinguished target. According to the hypothesis above, secondary extinction might be more readily observed in these rats than in the rats tested with a nonextinguished target CS. 
Table 1 The designs of Experiments 1, 2, and 3

\begin{tabular}{lccccc}
\hline Group & Conditioning & Ext X & Ext Y & Test X \\
\hline Experiment 1 & All phases conducted in the same context \\
SE & $(12 \mathrm{X}+$ & $(12 \mathrm{X}+$ & - & $16 \mathrm{Y}-$ & $8 \mathrm{X}-$ \\
$\mathrm{NE}$ & $(12 \mathrm{X}+$ & $12 \mathrm{Y}+)$ & - & - & $8 \mathrm{X}-$ \\
SE-ExtX & $(12 \mathrm{X}+$ & $12 \mathrm{Y}+)$ & $8 \mathrm{X}-$ & $16 \mathrm{Y}-$ & $8 \mathrm{X}-$ \\
NE-ExtX & $(12 \mathrm{X}+$ & $12 \mathrm{Y}+)$ & $8 \mathrm{X}-$ & - & $8 \mathrm{X}-$ \\
Experiment 2 & $\mathrm{Context} \mathrm{A}$ & Context B & Context C \\
SE & $(12 \mathrm{X}+$ & $12 \mathrm{Y}+)$ & - & $(8 \mathrm{Y}-$ & $4 \mathrm{X}-)$ \\
NE & $(12 \mathrm{X}+$ & $12 \mathrm{Y}+)$ & - & $(-$ & $4 \mathrm{X}-)$ \\
SE-ExtX & $(12 \mathrm{X}+$ & $12 \mathrm{Y}+)$ & $8 \mathrm{X}-$ & $(8 \mathrm{Y}-$ & $4 \mathrm{X}-)$ \\
NE-ExtX & $(12 \mathrm{X}+$ & $12 \mathrm{Y}+)$ & $8 \mathrm{X}-$ & $(-$ & $4 \mathrm{X}-)$ \\
Experiment 3 & - All phases conducted in the same context & \\
SE-Mix & $(4 \mathrm{X}+$ & $4 \mathrm{Y}+)$ & & $(6 \mathrm{Y}-$ & $4 \mathrm{X}-)$ \\
NE-Mix & $(4 \mathrm{X}+$ & $4 \mathrm{Y}+)$ & & $(-$ & $4 \mathrm{X}-)$ \\
SE-Sep & $(4 \mathrm{X}+)$ & $(4 \mathrm{Y}+)$ & & $(6 \mathrm{Y}-$ & $4 \mathrm{X}-)$ \\
NE-Sep & $(4 \mathrm{X}+)$ & $(4 \mathrm{Y}+)$ & & $(-$ & $4 \mathrm{X}-)$ \\
\hline
\end{tabular}

$\mathrm{X}$ and $\mathrm{Y}$ refer to different conditioned stimuli (counterbalanced); + and indicate conditioning and extinction trials, respectively; $-=$ context exposure; $\mathrm{SE}=$ secondary extinction; $\mathrm{NE}=$ no extinction; $\mathrm{ExtX}=$ extinction of $\mathrm{X}$; Mix =intermixed training; $\mathrm{Sep}=$ separate training

\section{Method}

\section{Subjects}

Thirty-two female Wistar rats (Charles River Laboratories, Quebec, Canada), ranging in age from 75 to 90 days at the start of the experiment, were individually housed in suspended stainless steel cages in a room maintained on a 16:8-h light:dark cycle. Experimental sessions were run during the light portion of the cycle at the same time each day. The rats were food deprived to $80 \%$ of their baseline body weights and were maintained at that level throughout the experiment. Water was freely available in the home cages.

\section{Apparatus}

Two sets of four operant chambers (Med Associates, St. Albans, VT) located in separate rooms were used. Chambers from both sets measured $31.8 \times 24.1 \times 29.2 \mathrm{~cm}(1 \times \mathrm{w} \times \mathrm{h})$ and were individually housed in windowed sound attenuation chambers. Ventilation fans provided background noise of $65 \mathrm{~dB}$, and the boxes were lit with two $7.5-\mathrm{W}$ incandescent bulbs mounted to the ceiling of the sound attenuation chamber. The front and back walls were brushed aluminum; the sidewalls and ceiling were clear acrylic plastic. Recessed $5.1 \times 5.1 \mathrm{~cm}$ food cups were centered in the front wall and positioned near floor level.
In one set of boxes, a 4.8-cm-long stainless steel operant lever protruded $1.9 \mathrm{~cm}$ from the front wall and was positioned $6.3 \mathrm{~cm}$ above the grid floor to the right of the food cup. The floor was composed of stainless steel rods $(0.48 \mathrm{~cm}$ in diameter) spaced $1.6 \mathrm{~cm}$ apart from center to center and mounted parallel to the front wall. The ceiling and left sidewall had black horizontal stripes, $3.8 \mathrm{~cm}$ wide and $3.8 \mathrm{~cm}$ apart. In the second set of boxes, the $4.8-\mathrm{cm}-$ long stainless steel operant lever protruded $1.9 \mathrm{~cm}$ from the front wall and was positioned $6.3 \mathrm{~cm}$ above the grid floor to the left of the food cup. The floor consisted of alternating stainless steel rods with different diameters $(0.48$ and $1.27 \mathrm{~cm})$, spaced $1.6 \mathrm{~cm}$ apart from center to center. The ceiling and left sidewall were covered with rows of dark dots $(1.9 \mathrm{~cm}$ in diameter $)$ that were separated by approximately $1.2 \mathrm{~cm}$. The 60-s light-off CS was created by terminating the houselights to produce darkness. The tone CS was a $60-\mathrm{s}$ presentation of a $3000-\mathrm{Hz}$ tone $(80 \mathrm{~dB})$ delivered through a $7.6-\mathrm{cm}$ speaker mounted to the ceiling of the sound attenuation chamber. The US was a $0.5-\mathrm{s}, 1-\mathrm{mA}$ shock provided by Med Associates shock sources. Leverpressing was reinforced with 45-mg MLab Rodent Tablets (TestDiet, Richmond, IN).

\section{Procedure}

The experiment involved daily 84-min sessions in which the rats leverpressed for food reinforcement. Training began after a week of daily handling and food restriction to attain the target body weights.

Leverpress training The rats were first trained to leverpress on a continuous reinforcement schedule, after which a variable interval (VI) 90-s reinforcement schedule was introduced and maintained throughout the remainder of the experiment. After seven sessions of baseline training, the rats were assigned to one of four groups $(n=8)$ matched on their baseline leverpressing rates and counterbalanced across chambers.

Conditioning and baseline recovery Two sessions of fear conditioning were conducted over 2 days. Each session consisted of six light-off and six tone presentations that coterminated with the shock US. The CSs were presented in an alternating fashion with an average intertrial interval (ITI) of $6 \mathrm{~min}$. The sequence (tone or light-off first) was counterbalanced across groups and sessions. The rats received a total of 12 conditioning trials with each $\mathrm{CS}$, which were counterbalanced within each group to serve as $\mathrm{X}$ and $\mathrm{Y}$. A baseline recovery day was conducted on the 3 rd day in order to recover leverpressing baselines that were depressed by fear conditioning. No CSs were presented during this session. 
Extinction and test Extinction was then conducted over 3 days following baseline recovery. On the 1st day, two groups of rats were given eight extinction trials of the target CS (X) with an average ITI of 9 min. The two remaining groups were given equivalent exposure to the context but did not undergo extinction. Over the next 2 days, one group of rats from each of these conditions (extinguished $\mathrm{X}$ and nonextinguished $\mathrm{X}$ ) were given eight extinction trials each session with the nontarget CS (Y). The remaining control groups were given equivalent time leverpressing in the context. On the final day, all rats were given eight test trials of $\mathrm{X}$. The factorial design yielded four groups: a simple secondary extinction group (SE) and a complementary noextinction control that did not undergo extinction of $\mathrm{Y}$ (NE), as well as a secondary extinction group in which $\mathrm{X}$ was partially extinguished on the 1st day of extinction (SEExtX) and a no-extinction control that likewise had partial extinction of $\mathrm{X}$ but no extinction of $\mathrm{Y}$ (NE-ExtX).

Data analysis The computer recorded the number of leverpresses for each rat during each $60-\mathrm{s}$ CS, as well as the 60-s period immediately preceding the CS. These data were used to calculate a suppression ratio, $C /(C+P)$, where $C$ is the number of responses made during the CS and $P$ is the number of responses made during the pre-CS period (Annau \& Kamin, 1961). A score of .5 denotes no leverpress suppression during the CS, whereas a score of 0 denotes complete suppression of responding during the CS. Suppression ratios were averaged across each block of two trials prior to statistical analysis. For this and the following experiments, analyses of variance (ANOVAs) with a rejection criterion of $p<.05$ were used.

\section{Results and discussion}

The results from extinction of $\mathrm{X}$ and $\mathrm{Y}$ and the test of $\mathrm{X}$ are presented in Fig. 1, which shows suppression to the CSs averaged in two-trial blocks. As the figure suggests, suppression to $\mathrm{X}$ was equivalent between the two groups during the first phase of extinction (left). During the extinction of $\mathrm{Y}$, however, significant group differences were present. The middle portion of Fig. 1 suggests that secondary extinction of $\mathrm{Y}$ occurred in the group that had received eight extinction trials of $\mathrm{X}$ in the preceding phase (Group SE-ExtX). Confirming this impression, a group $\times$ CS modality $\times$ block ANOVA showed that there was less suppression to $\mathrm{Y}$ in the SE-ExtX group than in the SE group, which had not undergone any prior extinction of $\mathrm{X}$, $F(1,12)=7.25$. This reduction persisted over both days of presentations of $\mathrm{Y}$. Thus, inconsistent with the notion that secondary extinction occurs only with target CSs that have themselves undergone some prior extinction, the effect was observed with a target CS (in this case, Y) that had not been previously extinguished. There was also a significant main effect of CS modality, $F(1,12)=16.72$, as well as significant $\mathrm{CS}$ modality $\times$ block and group $\times$ block interactions, $F_{S} \geq 2.67$, indicating more suppression, and slower extinction, with the light-off $\mathrm{CS}$. Baseline responding during the 1-min pre-CS periods was analyzed with a parallel ANOVA. No group differences in pre-CS scores were observed during the extinction of $\mathrm{Y}, F<1$. Average pre-CS responses were 30.6 and 28.3 in the SE-ExtX and SE groups, respectively, during the extinction of $\mathrm{Y}$.

The final test of $\mathrm{X}$ is displayed on the right in Fig. 1. As was expected, there was less overall suppression to $\mathrm{X}$ in the two groups for which $\mathrm{X}$ had been partially extinguished. This was confirmed by a significant main effect of extinction of $\mathrm{X}$ in an extinction of $\mathrm{X} \times$ extinction of $\mathrm{Y} \times \mathrm{CS}$ modality $\times$ block ANOVA, $F(1,24)=25.18$. However, there was no evidence that extinction of $\mathrm{Y}$ affected suppression to $\mathrm{X}$, whether $\mathrm{X}$ was partially extinguished or not, $F_{\mathrm{S}}<1$. As during extinction of $\mathrm{Y}$, a significant main effect of $\mathrm{CS}$ modality indicated greater overall suppression to the light, $F(1,24)=4.86$, although an interaction with extinction of $\mathrm{X}$ suggested that this disparity was greater in the groups for which $\mathrm{X}$ was not previously extinguished, $F(1,24)=4.53$, reflecting a possible ceiling effect in the extinguished-X groups. Analysis of pre-CS responding revealed a significant extinction of $\mathrm{Y} \times \mathrm{CS}$ modality interaction, $F(1,24)=$ 4.02. There was greater responding before light-off trials in the extinguished-Y groups, which averaged 32.0 pre-CS responses, than in the control groups, which averaged 22.4 responses. Average scores per group were 29.2, 25.0, 27.7, and 25.7 for the SE-ExtX, NE-ExtX, SE, and NE groups, respectively. There were no other group differences on the test, $F \mathbf{S}<1$.

The results of the second phase suggest that secondary extinction can be observed in the conditioned suppression preparation. However, the effect did not depend on prior

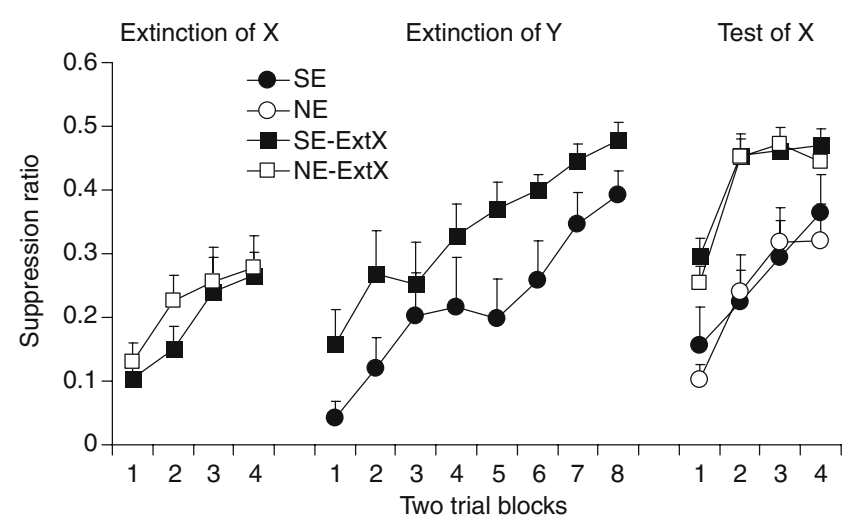

Fig. 1 Conditioned suppression during extinction of $\mathrm{X}$ and $\mathrm{Y}$ and the test of $\mathrm{X}$ in Experiment 1. See text and Table 1 for details 
extinction of the target CS. The group that received extinction trials with $\mathrm{X}$ in the first phase (SE-ExtX) clearly showed reduced suppression to $\mathrm{Y}$ in the second phase, even though $\mathrm{Y}$ had never been extinguished. The reduction in suppression to $\mathrm{Y}$ was evident even in the first two-trial block of extinction, $F(1,16)=4.70$, at which point $Y$ would have little opportunity to acquire an inhibitory association with the US and, thus, would not have been a suitable target for transfer of negative occasion setting by the context. It is not clear why a similar secondary extinction effect was not observed during the final test of X. However, the test of secondary extinction to $\mathrm{X}$ differed from the test of secondary extinction to $\mathrm{Y}$ in the number of extinction trials the alternate CS had received (16 vs. 8 ) and in the time between the end of conditioning and the start of the test (120 vs. $72 \mathrm{~h}$ ). The literature suggests that the strength of generalization between two stimuli may decrease with more extensive training (e.g., Hovland, 1937; Razran, 1949), which may be consistent with the failure to observe secondary extinction (a test of generalized extinction) after a larger number of extinction trials.

\section{Experiment 2}

Experiment 1 produced evidence that secondary extinction did not depend on prior extinction with the target CS. In fact, with the methods used in that experiment, there was no evidence that the partially extinguished CS (X) was sensitive to secondary extinction at all. One goal of Experiment 2 was therefore to provide a further test for secondary extinction with a partially extinguished CS. The design, which is summarized in Table 1, allowed us to investigate secondary extinction in the form of erasure of the renewal effect. As described above, Rescorla and Cunningham reported that nonreinforced presentations of one CS just before tests of reinstatement (1977) and spontaneous recovery (1978) of a second, extinguished, CS abolished those recovery effects. However, renewal, a related relapse phenomenon, has yet to be tested for erasure. In renewal, responding to an extinguished CS returns when it is tested outside of the extinction context (e. g., Bouton \& Bolles, 1979; Bouton \& King, 1983). Renewal effects have been observed when testing occurs back in the original conditioning context after extinction in a different one (i.e., ABA renewal), as well as when testing occurs in a neutral context (e.g., ABC renewal). Experiment 2 was designed to ask whether extinction of $\mathrm{Y}$ is able to erase renewal of $\mathrm{X}$ when $\mathrm{X}$ was conditioned in context $\mathrm{A}$, extinguished in context $\mathrm{B}$, and then tested for renewal in context $\mathrm{C}$. One of the groups (SE-ExtX) received renewal tests with $\mathrm{X}$ following extinction trials with $\mathrm{Y}$ in the same context.

\section{Method}

Subjects

Thirty-two female Wistar rats of the same age and purchased from the same supplier were used. The rats were housed and maintained under the same conditions as in Experiment 1.

\section{Apparatus}

The two sets of four operant chambers used in Experiment 1 were modified slightly for use as the extinction and test contexts ( $\mathrm{B}$ and $\mathrm{C}$, counterbalanced). To create distinct odors in the respective contexts, a dish containing $5 \mathrm{ml}$ of a $4 \%$ anise solution or a $8 \%$ coconut solution (McCormick \& Co Inc., Hunt Valley, MD) was placed outside of each chamber near the front wall. Two additional counterbalanced sets of four chambers were used as the conditioning context (A). Chambers in the first set measured $26 \times 25 \times$ $19 \mathrm{~cm}$. The front and back wallsand one sidewall were made of aluminum; the remaining sidewall and ceiling were clear acrylic plastic. The floor consisted of tubular steel rods, $1.6 \mathrm{~cm}$ in diameter and spaced $3.2 \mathrm{~cm}$ from center to center. A recessed $5.5 \times 5.5 \mathrm{~cm}$ food cup was centered on the front wall near the grid floor and was located to the left of the operant lever. Odor was provided by $5 \mathrm{ml}$ of white vinegar in a dish outside the chamber. Boxes in the second set measured $32 \times 25 \times 21 \mathrm{~cm}$; the front and rear walls, as well as the ceiling, were made of clear acrylic plastic, while the sidewalls were made of aluminum. The floor was made of stainless steel rods, $0.5 \mathrm{~cm}$ in diameter and spaced $1.5 \mathrm{~cm}$ apart. A recessed $5 \times 5 \mathrm{~cm}$ food cup was centered along the front wall at floor level and was located to the right of the operant lever. This set of chambers was scented with $1.0 \mathrm{ml}$ of Vick's Vaporub ${ }^{\mathrm{TM}}$ in a dish outside the chamber. Both sets of chambers were housed in sound-attenuating chambers illuminated by two $7.5-\mathrm{W}$ incandescent bulbs mounted to the ceiling. A fan in each chamber provided $65 \mathrm{~dB}$ of background noise. The CSs and food pellets were the same as those used in Experiment 1.

\section{Procedure}

The procedure was the same as that in Experiment 1, except as noted. Leverpress training occurred over six daily sessions, with half of the sessions conducted in each of the extinction and test contexts; three sessions occurred in context B (Days 1, 2, and 5), and three sessions occurred in context $\mathrm{C}$ (Days 3, 4, and 6). The rats were subsequently matched on their baseline leverpressing rates and were assigned to groups. Conditioning was conducted in context A, using the same sequence and arrangement of stimuli as 
in Experiment 1. A longer 1-s (1-mA) shock was employed to produce strong conditioning and, consequently, a strong renewal effect. Baseline recovery was conducted in context $\mathrm{B}$ in preparation for the extinction of $\mathrm{X}$ in that context.

Extinction and test Eight extinction trials with $\mathrm{X}$ were then presented in an 84-min session in context B. On the following day, the rats were placed in context $\mathrm{C}$ for a 112min session in which $\mathrm{Y}$ was extinguished and $\mathrm{X}$ was tested. One group of rats from each of these conditions (extinguished $\mathrm{X}$ and nonextinguished $\mathrm{X}$ ) were given eight nonreinforced trials of the nontarget $\mathrm{CS}$, Y, while the remaining control groups were given equivalent context exposure. Four test trials of $\mathrm{X}$ were subsequently presented to all groups immediately following the last extinction trial of Y. (The within-session testing method was based on the procedures used by Rescorla \& Cunningham, 1977, 1978.) The average ITI throughout the session was $9 \mathrm{~min}$. Comparison of the SE-ExtX and NE-ExtX groups on this test should show whether the extinction trials of $\mathrm{Y}$ preceding the test of $\mathrm{X}$ have the ability to erase renewed fear to $\mathrm{X}$, for which conditioning, extinction, and test occurred in contexts A, B, and C.

\section{Results}

Figure 2 summarizes the data from the extinction of $\mathrm{X}$ in context $\mathrm{B}$ and the extinction of $\mathrm{Y}$ and test of $\mathrm{X}$ in context $\mathrm{C}$. As was expected, the initial extinction of $\mathrm{X}$ proceeded without issue. Notably, however, significant group differences were present during the subsequent extinction of Y. There, a group $\times$ CS modality $\times$ block ANOVA showed that the SE-ExtX group showed less suppression to $\mathrm{Y}$ than did the SE control group, which did not undergo any prior extinction, $F(1,12)=4.84$. The result appears comparable to the result reported in Experiment 1. However, this secondary extinction effect was observed outside the context in which $\mathrm{X}$ had been extinguished.

On the final test of $\mathrm{X}$, an extinction of $\mathrm{X} \times$ extinction of $\mathrm{Y} \times \mathrm{CS}$ modality $\times$ block ANOVA failed to show a significant main effect of extinction of $\mathrm{Y}, F(1,24)=2.15$. However, a separate extinction of $\mathrm{X} \times$ extinction of $\mathrm{Y} \times \mathrm{CS}$ modality ANOVA conducted on the first two-trial block of the test revealed a main effect of extinction of $\mathrm{Y}, F(1,24)=$ 4.13. Thus, secondary extinction was observed on the test. There was also less overall suppression in the groups for which $\mathrm{X}$ had been previously extinguished, $F(1,24)=$ 12.57 , and less overall suppression to the tone, $F(1,24)=$ 7.21. To isolate the renewal effect in the two groups tested for renewal (SE-ExtX and NE-ExtX), we compared performance at the end of X's extinction in $\mathrm{B}$ with suppression to $\mathrm{X}$ at the start of testing in $\mathrm{C}$. A group $\times \mathrm{CS}$

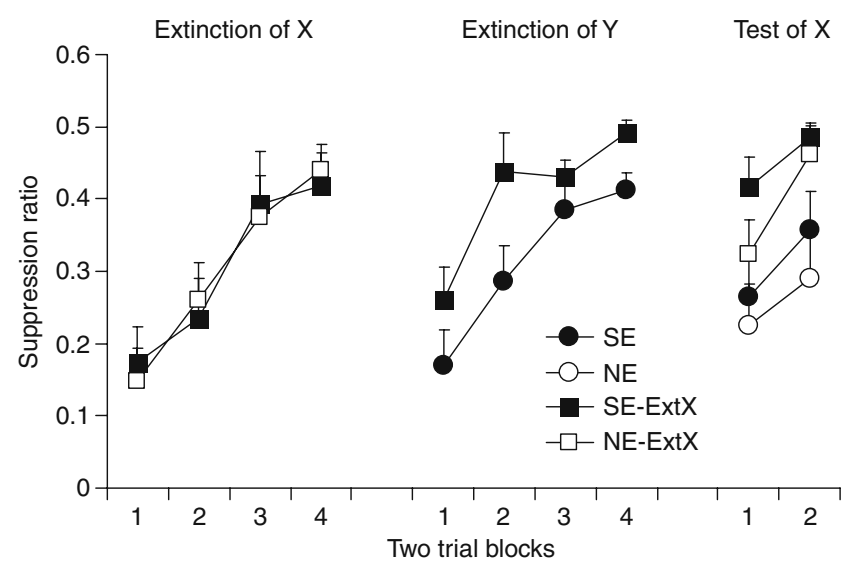

Fig. 2 Conditioned suppression during extinction of $\mathrm{X}$ and $\mathrm{Y}$ and the test of $\mathrm{X}$ in Experiment 2. See text and Table 1 for details

modality $\times$ block ANOVA failed to show a statistically significant block effect, $F(1,12)=4.23, p=.07$, or group $\times$ block interaction, $F(1,12)=4.07, p=.06$. However, different patterns emerged when the two groups were analyzed separately in parallel block $\times$ CS modality ANOVAs. There was a significant increase in suppression from extinction to test in the NE-ExtX control group, confirming an $\mathrm{ABC}$ renewal effect, $F(1,6)=10.01$. However, the corresponding difference did not approach significance in the SE-ExtX group, $F(1,6)<1$, suggesting that extinction of $\mathrm{Y}$ immediately prior to the test of $\mathrm{X}$ prevented (or erased) $\mathrm{ABC}$ renewal in this group. A main effect of CS modality was significant only for the groups that had not undergone extinction of $\mathrm{X}, F(1,6)=9.20$, consistent with the likelihood of a ceiling effect in the extinguished-X groups.

As usual, pre-CS response rates were analyzed with ANOVAs that paralleled the ones conducted on the suppression ratios. No group differences in pre-CS responding were found in any phase of the experiment, largest $F=$ 3.94. The average pre-CS responses during extinction of $Y$ were 20.0 and 21.2 in the SE-ExtX and NE-ExtX groups, respectively. On the final test of $X$, the scores were 21.6, 25.4, 19.3, and 21.7 in the SE-ExtX, NE-ExtX, SE and NE groups, respectively.

\section{Discussion}

In Experiment 2, we asked whether the erasure effect reported for reinstatement (Rescorla \& Cunningham, 1977) and spontaneous recovery (Rescorla \& Cunningham, 1978) also occurs with renewal. In keeping with the earlier reports, nonreinforced presentations of $\mathrm{Y}$ in context $\mathrm{C}$ shortly before a renewal test of $\mathrm{X}$ prevented renewal of conditioned suppression. The lack of $\mathrm{ABC}$ renewal in the SE-ExtX group extends the generality of the erasure effect to the renewal paradigm. 
It is worth noting that secondary extinction was also observed with $\mathrm{Y}$ when $\mathrm{X}$ had been previously extinguished in a different context. This result again indicates that secondary extinction can occur with a nonextinguished target. It might also suggest that secondary extinction, perhaps more than primary extinction, transfers between contexts. However, it is important to note that the context specificity of primary extinction is rarely complete. Indeed, the modest size of the $\mathrm{ABC}$ renewal effect observed in this experiment suggests that primary extinction does, in fact, transfer to some extent between contexts. Thus, although it is notable that secondary extinction transferred across contexts in this experiment, the experiment was not designed to test, and did not address, whether a context switch attenuates secondary extinction.

\section{Experiment 3}

In the experiments above, secondary extinction was found to occur whether or not the target CS had first undergone some extinction. The results thus disconfirmed our first hypothesis about the conditions required for secondary extinction. Experiment 3 therefore investigated another variable that emerged as potentially important in other unpublished experiments conducted in our laboratory. In those experiments, when $\mathrm{X}$ and $\mathrm{Y}$ were first conditioned in separate sessions, we found no evidence of secondary extinction (see also Bouton \& King, 1983). In Experiments 1 and 2, conditioning had occurred in sessions in which the target and nontarget stimuli were intermixed. Experiment 3 was therefore designed to ask experimentally whether intermixing conditioning trials with $\mathrm{X}$ and $\mathrm{Y}$ is required for the secondary extinction effect. As is illustrated in Table 1, X and $\mathrm{Y}$ were paired with shock over 2 days, either intermixed, as in Experiments 1 and 2, or in separate sessions conducted $24 \mathrm{~h}$ apart.

\section{Method}

\section{Subjects}

Thirty-two female Wistar rats of the same age and purchased from the same supplier were used. The rats were housed and maintained under the same conditions as in the previous experiments.

\section{Apparatus}

The operant chambers and all stimuli (tone and light-off CSs and a $0.5-\mathrm{s}, 1.0-\mathrm{mA}$ shock US) were the same as those used in Experiment 1.
Procedure

All phases of the experiment were conducted in the same physical context. After 1 week of daily handling and food restriction, the rats were trained to leverpress on a VI 90-s reinforcement schedule over eight daily 84-min sessions and then were matched on response rates and assigned to groups as before.

Conditioning The rats were given two 84-min sessions of fear conditioning with the tone and light-off CSs, counterbalanced to serve as $\mathrm{X}$ and $\mathrm{Y}$. Four trials were presented in each session. Two groups (SE-Mix and NE-Mix) were given two tone and two light-off trials in each session, presented in an alternating fashion, with an average ITI of $18 \mathrm{~min}$. For the remaining groups (SE-Sep and NE-Sep), all four conditioning trials of one CS occurred in the first session, and all four trials of the other CS in the second. The order of CS presentation was counterbalanced for both CS modality (tone or light-off first) and CS type (X or Y first).

Extinction and test The extinction of $\mathrm{Y}$ and test of $\mathrm{X}$ were conducted in a single 112-min session following a baseline recovery day. Two groups of rats were given six extinction trials of $\mathrm{Y}$, while the remaining groups were given equivalent context exposure. Four test trials of $\mathrm{X}$ were presented after the last extinction trial. An average ITI of 9 min was maintained throughout the session.

Data analysis Baseline leverpressing was lost in 3 subjects after the first test trial of $\mathrm{X}$ (highest mean rate over the remaining three trials was 0.67 responses per minute). The data from those rats, 2 from the NE-Mix group and 1 from the SESep group, were consequently not included in the analysis.

\section{Results and discussion}

Figure 3 summarizes the data from the extinction of $Y$ and test of $\mathrm{X}$. As the graph makes evident, suppression to $\mathrm{Y}$ during extinction was equivalent between groups and comparable to the levels of suppression observed in the previous experiments. The fact that both groups performed similarly during this phase, particularly on the first block of extinction, suggests that the intermixed and separated conditioning treatments created comparable fear to the CS. A group $\times$ CS modality $\times$ block ANOVA on the extinction data with $\mathrm{Y}$ showed a significant block effect, $F(2,22)=12.89$, and CS modality effect, $F(1,11)=7.35$, indicating greater suppression to the light-off CS. Neither the group effect nor any of the interactions were significant, $F_{\mathbf{S}}<1$. More important, however, the test data revealed a secondary extinction effect only in the group that received the intermixed 
treatment. A conditioning group $\times$ extinction group $\times$ CS modality $\times$ block ANOVA conducted on the test data showed a main effect of extinction, $F(1,21)=6.30$, a factor that importantly interacted with the conditioning treatment, $F(1,21)=5.86$. Planned comparisons confirmed that extinction of $\mathrm{Y}$ reduced suppression to $\mathrm{X}$ in the SE-Mix group only, $F(1,10)=11.07$. The same effect was not observed in the SE-Sep group, $F(1,11)<1$. Thus, it appears that intermixing the conditioning trials of the target and nontarget stimuli was necessary for secondary extinction to occur. Significant main effects of CS modality indicating greater suppression to the light-off CS were also observed in the main ANOVA, $F(1,21)=19.72$, as well as both of the subsequent comparisons, $F(1,10)=7.58$ and $F(1,11)=12.65$, respectively. No differences in pre-CS scores were observed between groups in either the extinction or the test phase, largest $F=$ 2.96. Pre-CS responding during the extinction phase averaged 20.2 and 24.7 for the SE-Mix and SE-Sep groups, respectively, and 22.6, 16.7, 24.2, and 24.5 on the test for the SEMix, NE-Mix, SE-Sep, and NE-Sep groups, respectively.

These results again indicate that secondary extinction can occur when the target CS has never been extinguished. However, they strongly implicate intermixed conditioning trials with $\mathrm{X}$ and $\mathrm{Y}$ as a necessary condition for producing the effect. Importantly, the lack of a secondary extinction effect in the groups given separate conditioning sessions with each CS also indicates that the present result is not merely a result of direct generalization between the tone and light-off CSs or pairings with a common US during the acquisition phase. The absence of the effect in those groups is also consistent with the previous results of Bouton and King (1983).

\section{General discussion}

Since Pavlov's (1927/1960) initial discovery of secondary extinction, few studies have reported a similar pattern of results. The present series of experiments, however, demonstrated that a robust and replicable secondary extinction effect can be obtained in Pavlovian fear conditioning. They also provided information about the role of two variables that might be involved in producing it. First, we have previously suggested that primary extinction depends on negative occasion setting acquired by the extinction context (e.g., Bouton, 2004). Such contextual occasion setting might create secondary extinction if it transferred to a second CS tested in the same context. Given the fact that conditioned-then-extinguished targets seem especially sensitive to the effects of such a process (e.g., Swartzentruber \& Rescorla, 1994), it seemed possible that an extinguished CS might be especially sensitive to secondary extinction. Although Experiment 2 demonstrated that extinction of one $\mathrm{CS}$ was sufficient to erase $\mathrm{ABC}$ renewal of

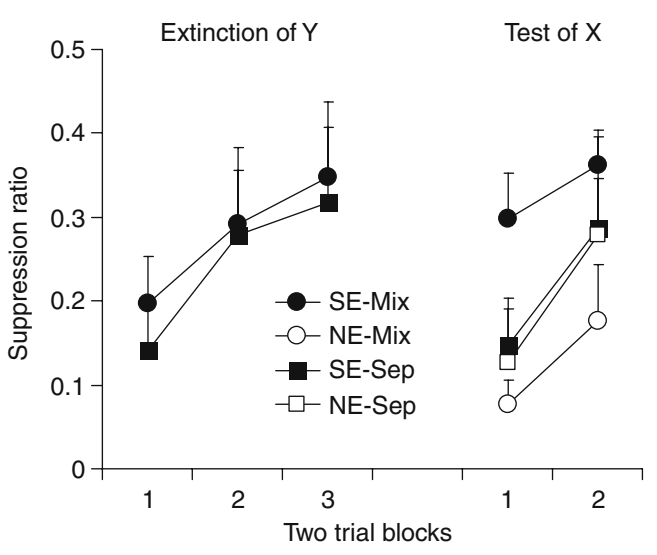

Fig. 3 Extinction of $\mathrm{Y}$ and Test of $\mathrm{X}$ in Experiment 3. See text and Table 1 for details

another extinguished CS (cf. Rescorla \& Cunningham, 1977, 1978), all three experiments produced evidence that secondary extinction does not require previous extinction of the target CS. Second, in Experiment 3, we showed that intermixing conditioning trials with both CSs is critical for secondary extinction to occur. Although we consistently observed secondary extinction in groups that received an intermixed conditioning procedure (Experiments 1-3), the effect was abolished when $\mathrm{X}$ and $\mathrm{Y}$ received conditioning in distinct sessions separated by $24 \mathrm{~h}$ (Experiment 3 ).

Fundamentally, a test for secondary extinction is a test of generalization of extinction between $\mathrm{X}$ and $\mathrm{Y}$. There was little physical generalization between the auditory and visual CSs used in these experiments, as demonstrated by the failure to observe secondary (or generalized) extinction under some conditions (Experiment 3). However, other forms of learned generalization might allow transfer of extinction between $\mathrm{X}$ and $\mathrm{Y}$. Kehoe (1988) proposed a connectionist model in which CSs paired with a US acquire associations (1) between the CS and a hidden unit that is (2) in turn associated with another unit that activates the response (the response unit). Because CSs associated with the same US are posited to share the same hidden-unitresponse-unit association, conditioning with one $\mathrm{CS}$ will make conditioning with a second CS more rapid, because it has already created the shared hidden-unit-response-unit association. Although Kehoe emphasized this form of "learning to learn," in which excitatory conditioning of one CS increases the rate of conditioning of a second CS, the model would also permit secondary extinction, because extinction of $Y$ would analogously weaken the hidden-unitresponse-unit association shared by $\mathrm{X}$ and $\mathrm{Y}$. A related account of secondary extinction would emphasize the role of mediated generalization or acquired equivalence. For example, Honey and Hall (1989) reported that conditioned suppression generalized more readily from one CS to another if both stimuli had been previously associated with 
the same US (food pellets). Their findings indicate that generalization between two physically different stimuli can be increased if they are associated with a common eventin effect, by increasing the number of elements they share (e.g., Hall, 2007). Such acquired equivalence could contribute to secondary extinction because $\mathrm{X}$ and $\mathrm{Y}$ are associated with a common US during the initial conditioning phase. However, a significant challenge for this mechanism and the Kehoe (1988) mechanism is that neither anticipates the finding that intermixed conditioning trials with $\mathrm{X}$ and $\mathrm{Y}$ can yield secondary extinction, whereas separated conditioning trials do not (Experiment 3).

The fact that $\mathrm{X}$ and $\mathrm{Y}$ must be conditioned in the same session to enable secondary extinction instead suggests that time between trials plays a role in secondary extinction. One possibility is that the animals simply associate $\mathrm{X}$ and $\mathrm{Y}$ over the ITI when conditioning trials are intermixed. If that were the case, subsequent extinction trials with $\mathrm{Y}$ might also excite a representation of $\mathrm{X}$, allowing extinction of $\mathrm{X}$ to occur indirectly. Such an effect would be analogous to the mediated extinction effect reported by Shevill and Hall (2004). In three experiments, rats were initially given conditioning with two compound stimuli, AX and BY. In the following phase, A was extinguished alone. The authors reported that on a subsequent test, suppression to $\mathrm{X}$ was attenuated as compared with $\mathrm{Y}$, whose associate (B) had not been extinguished. Similarly, Ward-Robinson and Hall (1996) reported a mediated extinction effect with a target CS that had been paired with its associate during a sensory preconditioning phase.

We have no direct evidence, however, that rats can learn to associate visual and auditory cues when they are separated by the long ITIs (6 or $18 \mathrm{~min}$ ) used here. An alternative hypothesis might go as follows. Bouton (1993) has argued that time can function as a context and that the passage of time can produce context change. For example, adding a retention interval after extinction produces spontaneous recovery, an effect akin to the renewal effect (e.g., Brooks \& Bouton, 1993). It is thus possible that the 24-h interval between the conditioning of $\mathrm{X}$ and $\mathrm{Y}$ in the separate condition caused them to be associated with different temporal contexts and that shorter intervals between $\mathrm{X}$ and $\mathrm{Y}$ in the intermixed condition caused them to be associated with the same temporal context. In the latter case, the greater generalization between $\mathrm{X}$ and $\mathrm{Y}$ may be due to their shared association with the common temporal context, creating a new form of acquired equivalence or mediated generalization. Interestingly, the present results and explanation are compatible with recent human memory research. In paired associate learning, human participants make intrusion errors during cued recall tests by reporting items from nearby paired associates; the probability of such intrusions is a function of the intruding item's proximity to the target item in the list (Davis, Geller, Rizzuto, \& Kahana, 2008). This and other related phenomena have been explained by a formal version of the idea that during list learning, associations are formed between items and their local temporal contexts. During recall, retrieval of an item also retrieves its temporal context, which then retrieves nearby items sharing a similar temporal context (Sederberg, Howard, \& Kahana, 2008). An analogous mechanism in the present experiments would encourage retrieval of $X$ during extinction of $\mathrm{Y}$ after intermixed conditioning and, thus, the secondary extinction effect observed here.

Additional research will be necessary to fully understand the role of trial intermixing in creating secondary extinction. First, in studies of perceptual learning, intermixed presentations of highly similar stimuli appear to enhance the discrimination, rather than generalization, between them (e.g., Mondragón \& Murphy, 2010; Symonds \& Hall, 1995). Although such results appear to contradict the present ones, they may well be unique to the highly similar stimuli that are studied in perceptual learning research. The tone and light-off CSs employed here were different, rather than similar (there is little evidence of generalization between them). There is some evidence, perhaps compatible with the present results, that intermixed exposures to two very different stimuli can make them more difficult to discriminate (Chantrey, 1972). Second, the literature suggests that the relationship between trial intermixing and secondary extinction may be complex. Consistent with a role for trial intermixing, Bouton and King (1983) did not intermix and did not observe secondary extinction. Five out of seven positive experiments reported by Rescorla and Cunningham $(1977,1978)$ involved intermixed conditioning trials, and the two that did not (Rescorla \& Cunningham, 1977, Experiment 2; Rescorla \& Cunningham, 1978, Experiment 2) involved intermixed exposures to the CSs before conditioning. Ledgerwood et al. (2005) used intermixed conditioning trials and found secondary extinction when extinction was combined with DCS (although not when it was not). In contrast, both Richards and Sargent (1983) and Kasprow et al. (1984) used intermixed conditioning trials with primarily negative results. Although all positive reports of secondary extinction appear to have involved some intermixed exposures to $\mathrm{X}$ and $\mathrm{Y}$, trial mixing does not guarantee the effect. Nonetheless, the results of the present Experiment 3 unequivocally suggest that intermixed conditioning trials help to enable secondary extinction.

In summary, the present results encourage the view that secondary extinction may be a reliable phenomenon in fear conditioning and that it might depend on learning mechanisms that encourage generalization between the CSs. Importantly, that generalization may be facilitated by intermixed, rather than separate, conditioning trials with the two CSs during the initial conditioning phase. 


\section{References}

Annau, Z., \& Kamin, L. J. (1961). The conditioned emotional response as a function of intensity of the US. Journal of Comparative and Physiological Psychology, 54, 253-272.

Bouton, M. E. (1993). Context, time, and memory retrieval in the interference paradigms of Pavlovian learning. Psychological Bulletin, 114, 80-99.

Bouton, M. E. (2004). Context and behavioral processes in extinction. Learning \& Memory, 11, 485-494.

Bouton, M. E., \& Bolles, R. C. (1979). Contextual control of the extinction of conditioned fear. Learning and Motivation, 10, 445-466.

Bouton, M. E., \& King, D. A. (1983). Contextual control of the extinction of conditioned fear: Tests for the associative value of the context. Journal of Experimental Psychology: Animal Behavior Processes, 9, 248-265.

Brooks, D. C., \& Bouton, M. E. (1993). A retrieval cue for extinction attenuates spontaneous recovery. Journal of Experimental Psychology: Animal Behavior Processes, 19, 77-89.

Chantrey, D. F. (1972). Enhancement and retardation of discrimination learning in chicks after exposure to the discriminanda. Journal of Comparative and Physiological Psychology, 81, 256-261.

Davis, O. C., Geller, A. S., Rizzuto, D. S., \& Kahana, M. J. (2008). Temporal associative processes revealed by intrusions in pairedassociate recall. Psychonomic Bulletin \& Review, 15, 64-69.

Hall, G. (2007). Learned changes in stimulus representations (a personal history). The Spanish Journal of Psychology, 10, 218-229.

Honey, R. C., \& Hall, G. (1989). Acquired equivalence and distinctiveness of cues. Journal of Experimental Psychology: Animal Behavior Processes, 15, 338-346.

Hovland, C. I. (1937). The generalization of conditioned responses: IV. The effects of varying the amounts of reinforcement upon the degree of generalization of conditioned responses. Journal of Experimental Psychology, 21, 261-276.

Kasprow, W. J., Schachtman, T. R., Cacheiro, H., \& Miller, R. R. (1984). Extinction does not depend upon degradation of event memories. Bulletin of the Psychonomic Society, 22, 95-98.

Kehoe, E. J. (1988). A layered network model of associative learning: Learning to learn and configuration. Psychological Review, 95, 411-433.

Lamarre, J., \& Holland, P. C. (1987). Transfer of inhibition after serial feature negative discrimination training. Learning and Motivation, 18, 319-342.

Ledgerwood, L., Richardson, R., \& Cranney, J. (2005). DCycloserine facilitates extinction of learned fear: Effects on reacquisition and generalized extinction. Biological Psychiatry, 57, 841-847.

Mondragón, E., \& Murphy, R. A. (2010). Perceptual learning in an appetitive Pavlovian procedure: Analysis of the effectivess of the common element. Behavioural Processes, 83, 247-256.

Pavlov, I. P. (1960). Conditioned reflexes (G. V. Anrep, Trans.). New York: Dover. (Original work published 1927)

Razran, G. (1949). Stimulus generalization of conditioned responses. Psychological Bulletin, 46, 337-365.

Rescorla, R. A., \& Cunningham, C. L. (1977). The erasure of reinstated fear. Animal Learning \& Behavior, 5, 386-394.

Rescorla, R. A., \& Cunningham, C. L. (1978). Recovery of the US representation over time during extinction. Learning and Motivation, 9, 373-391.

Richards, R. W., \& Sargent, D. M. (1983). The order of presentation of conditioned stimuli during extinction. Animal Learning \& Behavior, 11, 229-236.

Sederberg, P. B., Howard, M. W., \& Kahana, M. J. (2008). A contextbased theory of recency and contiguity in free recall. Psychological Review, 115, 893-912.

Shevill, I., \& Hall, G. (2004). Retrospective revaluation effects in the conditioned suppression procedure. The Quarterly Journal of Experimental Psychology, 57B, 331-347.

Swartzentruber, D., \& Rescorla, R. A. (1994). Modulation of trained and extinguished stimuli by facilitators and inhibitors. Animal Learning \& Behavior, 22, 309-316.

Symonds, M., \& Hall, G. (1995). Perceptual learning in flavour aversion conditioning: Roles of stimulus comparison and latent inhibition of common stimulus elements. Learning and Motivation, 26, 203-219.

Vervliet, B. (2008). Learning and memory in conditioned fear extinction: Effects of D-cycloserine. Acta Psychologica, 127, 601-613.

Ward-Robinson, J., \& Hall, G. (1996). Backward sensory preconditioning. Journal of Experimental Psychology: Animal Behavior Processes, 22, 395-404.

\section{Author Note}

This research was supported by Grant RO1 MH064847 from the National Institute of Mental Health. The experiments were submitted as a part of a thesis that DV completed to fulfill requirements of a master's degree. Send correspondence to either author at the Department of Psychology, University of Vermont, 2 Colchester Ave, Burlington, VT, 05405-0134. 